Pak. J. Anal. Environ. Chem. Vol. 20, No. 1 (2019) 67 - 74

\title{
Assessment of Heavy Metals in Rice Using Atomic Absorption Spectrophotometry - A Study of Different Rice Varieties in Pakistan
}

\author{
Agha Arslan Wasim*, Sumaira Naz, Muhammad Nasiruddin Khan and \\ Saba Fazal-ur-Rehman \\ *Department of Chemistry, University of Karachi, Karachi-75270, Pakistan. \\ *Corresponding Author Email: arslan.wasim@uok.edu.pk \\ Received 09 April 2019, Revised 15 May 2019, Accepted 16 May 2019
}

\begin{abstract}
Accumulation of heavy metals in human body is known to possess quite toxic effects. They are ubiquitously found in earth crust and tend to accumulate in crops grown in heavily contaminated soil and hence enter the food chain. This study was based on the analysis of heavy metals in eighteen selected varieties of rice (Oryza sativa L.) that circulates in local market of Karachi, Pakistan. Few heavy metals namely, Cadmium $(\mathrm{Cd})$, Chromium $(\mathrm{Cr})$, Cobalt $(\mathrm{Co})$, Copper $(\mathrm{Cu})$, Lead $(\mathrm{Pb})$, Manganese $(\mathrm{Mn})$, Nickel $(\mathrm{Ni})$, and Zinc $(\mathrm{Zn})$ were analyzed using Atomic Absorption Spectroscopy (AAS). Rice samples were digested using nitric acid (conc.). Average concentrations of $\mathrm{Cd}, \mathrm{Co}, \mathrm{Cr}, \mathrm{Pb}, \mathrm{Ni}$ were $7.3,10.6,107,117,139 \mu \mathrm{g} \mathrm{kg}^{-1}$ of rice respectively, whereas, the respective concentrations of $\mathrm{Cu}, \mathrm{Mn}$, and $\mathrm{Zn}$ were found to be $4.7,9.7$, and $14.6 \mathrm{mg} \mathrm{kg}^{-1}$ of rice. The results from this study when compared with previous studies revealed that the Pakistani rice is found to have relatively less concentration of these heavy metals.
\end{abstract}

Keywords: Rice, Heavy metals, Atomic absorption spectrophotometry.

\section{Introduction}

During the past few decades, the contamination of soil by heavy metals has become a severe issue [1]. The sources of these contaminations are human activities, like industrial activities, mining, use of pesticides and chemicals, and wastewater irrigation [2-5]. Some heavy metals are essential heavy metal because body needs these metals at low level [6]. Example of essential heavy metals are $\mathrm{Mn}, \mathrm{Fe}, \mathrm{Cu}$ and $\mathrm{Zn}$. Other metals, like $\mathrm{Cr}, \mathrm{Cd}, \mathrm{Pb}$ and $\mathrm{As}$ are toxic and may pose a great threat to living organisms [7]. Heavy metals are present in soils in various forms which is responsible for their different levels of solubility [8]. Heavy metals may be present as structural component in soil lattice, they may be part of soil solution in dissolved form, they may also exist as exchangeable component while sometimes they are insolubly precipitated [911]. Normally the components which are present in soil solution or exchangeable (organic or inorganic) are absorbed by plants [12]. Hence absorption or uptake of heavy metal in soil mainly depends upon its solubility and availability in soil [13]. Uptake of metals by plants is also directly related to the concentration of heavy metals [14]. It means if the concentration of heavy metals increases in soil due to urbanization or industrialization it will lead to greater absorption of heavy metals in plants which subsequently pose a great threat to human health. Therefore, it is necessary to analyze agricultural land for heavy metal accumulation for safe and healthy crop production [15-17].

Rice (Oryza Sativa L.) is one of the most important cash crops that play a vital role in uplifting Pakistan's economy. It contributes more than two million tons to our food requirements and is an important source of employment and income 
generation for rural areas in the rice zone. It also contributes significantly in the foreign exchange earnings. Its importance in the national economy needs no emphasis as it accounts for $\approx 6$ percent of the total value added in agriculture and about 1.3 percent to GDP [18]. As rice crop plays a very important role in Pakistan's economy so any degradation in its quality, which ultimately result in economy fall, is highly unacceptable. Pakistan has two major rice-producing provinces, namely Punjab and Sindh. Both provinces account for more than 88 percent of total rice production.

The content of the essential elements and heavy metals, $\mathrm{Cu}, \mathrm{Cr}, \mathrm{Fe}, \mathrm{Mn}, \mathrm{Zn}, \mathrm{Se}$ etc. in the different brands of rice have been extensively studied [19-22]. Presence of heavy metal in rice is very dangerous for human health [13, 17]. Contamination of soil with heavy metals during cultivation of rice is major source for presence of heavy metals in rice [23]. The presence of heavy metals $(\mathrm{Cu}, \mathrm{Hg}, \mathrm{Zn}, \mathrm{As}, \mathrm{Pb}, \mathrm{Cd}, \mathrm{Ca}, \mathrm{Ni}, \mathrm{Mn}, \mathrm{Fe}$ and $\mathrm{Cr}$ ) more than their normal ranges in premises to cultivating soil is dangerous. Their content should be controlled in soil because it directly leads to the contamination of heavy metals in the plant [24]. Heavy metals are more dangerous relative to other pollutants in natural environment. As the elevated concentration of heavy metals leads to cause dangerous diseases in human [25]. Arsenic (As) high concentration in rice cause severe skin diseases and severe cancer-causing death in rice growing countries whose soil has large concentration of As [26]. It naturally occurs in the environment as an odorless, tasteless, semimetal element. It can get into drinking water supplies drawn from groundwater that contains As from natural deposits in the earth or from agricultural and industrial practices. Similarly, $\mathrm{Pb}$ causes severe health risk diseases in human beings especially brain disorders [5].

Rice is widely used as a staple food in the Asian countries. Therefore, it is very necessary to find the presence of heavy metals in rice and compare their concentration with normal ranges to ensure that either their presence is harmful to human health or not. Analysis of rice for heavy metals not only provides information about the quality of crop, it also acts as an indicator of the extent of contamination in crop field soil [27]. Hence in this study rice was analyzed for its heavy metal content. Rice samples were taken from different markets in Karachi, Pakistan which includes rice varieties coming from all over Pakistan.

\section{Materials and Methods \\ Chemical and reagents}

The reagents used in the analysis of rice sample were as per European Pharmacopoeia specifications. Nitric acid 69\% was obtained from Merck (Darmstadt, Germany). Distilled deionized water with specific conductance $<10 \mu \mathrm{S} \mathrm{cm}^{-1}$ was used to prepared samples. Certified stock standards for calibration $\left(1000 \mu \mathrm{g} \mathrm{mL}^{-1}\right)$ were used for the analysis.

\section{Sampling}

Eighteen rice grains samples were purchased from grocery markets of Karachi, Pakistan. These samples represented the most important brands of rice sold in the whole city. Each sample was a composite of the rice samples of same variety bought from different markets of the city. The selection of sample for each brand was random.

\section{Sample preparation}

All samples were washed with tap water (three times) followed by distilled water (twice). The samples were first air dried overnight and then dried in an oven at $65{ }^{\circ} \mathrm{C}$ for $2-3 \mathrm{~h}$ [28]. The samples were homogenized by grinding with a glass mortar. The rice flour from each sample was sieved from $428 \mu \mathrm{m}$ sieve and stored in airtight plastic bags. Concentrated nitric acid was used for the digestion of samples as per the procedure reported in literature.

\section{Digestion of rice samples}

A rice sample, $3-10 \mathrm{~g}$, was weighed accurately on an analytical balance and transferred to a beaker. The rice flour was then soaked in 30 $\mathrm{mL}$ of concentrated nitric acid for four days. Sample solutions were then boiled gently on hot 
plate till the solution became transparent and the evolution of brown fumes stopped. The digestion liquor was cooled down to room temperature and filtered through $0.45 \mu \mathrm{m}$ filter paper (Whatman 41). Filtrate and the washing of samples were finally diluted to $25.0 \mathrm{~mL}$ with deionized water [11].

\section{Instrumentation}

Perkin Elmer 2380 atomic absorption spectrophotometer was used in Flame atomic absorption mode for the determination of $\mathrm{Cd}, \mathrm{Co}$, $\mathrm{Cr}, \mathrm{Pb}, \mathrm{Ni}, \mathrm{Cu}, \mathrm{Mn}$, and $\mathrm{Zn}$. Acetylene was used as fuel while compressed air was used as oxidant. Hollow cathode lamps of the elements were used while the slit width was set at $0.7 \mathrm{~nm}$. Calibration standards series was prepared for each element by serial dilution of certified calibration standards for atomic absorption spectrophotometry. The instrument was optimized for lamp alignment, fuel-oxidant ratio, wavelength, and flame height. The wavelengths used for analysis along with their respective sensitivity and detection limits are shown in (Table 1).
Table 1. Wavelengths used for the analysis of selected heavy metals with corresponding sensitivity and detection limits.

\begin{tabular}{cccc}
\hline $\begin{array}{c}\text { Heavy } \\
\text { Metals }\end{array}$ & $\begin{array}{c}\text { Wavelength } \\
\text { nm }\end{array}$ & $\begin{array}{c}\text { Sensitivity } \\
\text { mg L }^{-\mathbf{1}}\end{array}$ & $\begin{array}{c}\text { Detection } \\
\text { Limits } \\
\text { mg L }^{-1}\end{array}$ \\
\hline Cd & 228.8 & 0.028 & 0.0005 \\
Co & 240.7 & 0.12 & 0.006 \\
$\mathbf{C r}$ & 357.9 & 0.078 & 0.002 \\
$\mathbf{C u}$ & 324.8 & 0.077 & 0.001 \\
$\mathbf{P b}$ & 217 & 0.19 & 0.01 \\
$\mathbf{M n}$ & 279.5 & 0.052 & 0.001 \\
$\mathbf{N i}$ & 232 & 0.14 & 0.004 \\
$\mathbf{Z n}$ & 213.9 & 0.018 & 0.0008 \\
\hline
\end{tabular}

\section{Results and Discussion}

In this study, selected taxonomic varieties of rice were analyzed using atomic absorption spectrophotometry for heavy metal in their grains. The rice varieties along with their sample ID and heavy metal concentrations are summarized in (Table 2). A comparison of heavy metal concentrations in rice of different origin reported in previous studies and observed in present study is presented in (Table 3).

Table 2. Concentration of heavy metals in the selected rice varieties used in this study.

\begin{tabular}{|c|c|c|c|c|c|c|c|c|c|}
\hline Rice Variety & ID & $\begin{array}{c}\text { Cd } \\
\left(\mu \mathrm{gkg}^{-1}\right)\end{array}$ & $\begin{array}{c}\text { Co } \\
\left(\mu g k g^{-1}\right)\end{array}$ & $\begin{array}{c}\mathrm{Cr} \\
\left(\mu \mathrm{gkg}^{-1}\right)\end{array}$ & $\begin{array}{c}\mathrm{Pb} \\
\left(\mu g k g^{-1}\right)\end{array}$ & $\begin{array}{c}\mathrm{Ni} \\
\left(\mu \mathrm{gkg}^{-1}\right)\end{array}$ & $\begin{array}{c}\mathrm{Cu} \\
\left(\mathrm{mgkg}^{-1}\right)\end{array}$ & $\begin{array}{c}\text { Mn } \\
\left(\mathrm{mgkg}^{-1}\right)\end{array}$ & $\begin{array}{c}\mathrm{Zn} \\
\left(\mathrm{mgkg}^{-1}\right)\end{array}$ \\
\hline Kernal & S01 & $<\mathrm{BDL}$ & $6.0 \pm 0.0$ & $129 \pm 24.4$ & $171.0 \pm 37.5$ & $129.0 \pm 28.6$ & $6.0 \pm 3.0$ & $4.0 \pm 1.7$ & $11.0 \pm 1.7$ \\
\hline Tota -1 & $\mathrm{~S} 02$ & $6.9 \pm 1.7$ & $4.9 \pm 1.7$ & $47.0 \pm 21.6$ & $100.0 \pm 24.0$ & $188.0 \pm 14.6$ & $5.9 \pm 3.0$ & $2.9 \pm 3.0$ & $17.7 \pm 0.1$ \\
\hline Irri -9 & S03 & $<\mathrm{BDL}$ & $<\mathrm{BDL}$ & $67.0 \pm 4.6$ & $41.0 \pm 13.6$ & $67.0 \pm 7.5$ & $4.8 \pm 1.7$ & $6.8 \pm 1.7$ & $33.0 \pm 8.9$ \\
\hline Thalla & S04 & $13.0 \pm 6.9$ & $8.0 \pm 1.7$ & $99.0 \pm 20.4$ & $126.0 \pm 75.5$ & $132.0 \pm 35.2$ & $4.0 \pm 1.7$ & $6.0 \pm 0.2$ & $14.0 \pm 3.5$ \\
\hline Tota Kernal - 1 & S05 & $22.0 \pm 4.4$ & $7.6 \pm 1.7$ & $75.0 \pm 2.5$ & $166.0 \pm 61.5$ & $103.0 \pm 25.4$ & $6.7 \pm 1.7$ & $4.8 \pm 1.6$ & $12.4 \pm 1.6$ \\
\hline Tota Kernal - 2 & S06 & $20.5 \pm 3.0$ & $6.8 \pm 3.4$ & $62.0 \pm 9.1$ & $129.0 \pm 20.0$ & $100.0 \pm 16.2$ & $8.8 \pm 0.1$ & $4.9 \pm 1.7$ & $11.7 \pm 7.7$ \\
\hline Super Kernal Basmati & S07 & $8.1 \pm 0.2$ & $8.0 \pm 0.1$ & $127.0 \pm 19.6$ & $<\mathrm{BDL}$ & $207.0 \pm 8.0$ & $9.3 \pm 2.3$ & $5.3 \pm 4.6$ & $10.6 \pm 4.6$ \\
\hline Super Basmati & S08 & $<\mathrm{BDL}$ & $2.8 \pm 0.2$ & $54.0 \pm 9.6$ & $54.0 \pm 10.3$ & $80.0 \pm 17.1$ & $3.3 \pm 0.9$ & $4.7 \pm 1.7$ & $13.3 \pm 3.3$ \\
\hline Super Basmati Shaheen & S09 & $<\mathrm{BDL}$ & $3.8 \pm 1.7$ & $40.0 \pm 12.5$ & $273.0 \pm 19.6$ & $60.0 \pm 7.1$ & $9.5 \pm 1.7$ & $8.5 \pm 0.1$ & $11.4 \pm 2.9$ \\
\hline Dani Basmati & $\mathrm{S} 10$ & $<\mathrm{BDL}$ & $6.6 \pm 0.2$ & $86.0 \pm 7.0$ & $<\mathrm{BDL}$ & $86.0 \pm 15.6$ & $8.8 \pm 1.9$ & $6.6 \pm 0.1$ & $11.0 \pm 3.8$ \\
\hline Basmati & $\mathrm{S} 11$ & $<\mathrm{BDL}$ & $<\mathrm{BDL}$ & $77.0 \pm 25.3$ & $<\mathrm{BDL}$ & $116.0 \pm 16.7$ & $11.2 \pm 2.8$ & $9.6 \pm 0.3$ & $12.8 \pm 5.6$ \\
\hline Basmati - 110 & $\mathrm{~S} 12$ & $6.3 \pm 5.4$ & $9.4 \pm 0.1$ & $38.0 \pm 9.5$ & $113.0 \pm 16.2$ & $141.0 \pm 23.7$ & $14.1 \pm 0.0$ & $9.4 \pm 0.1$ & $18.9 \pm 0.1$ \\
\hline Irri - 9 (Punjab) & $\mathrm{S} 13$ & $9.0 \pm 0.0$ & $9.0 \pm 0.2$ & $171.0 \pm 63.0$ & $117.0 \pm 10.4$ & $153.0 \pm 39.2$ & $16.5 \pm 2.6$ & $9.0 \pm 0.2$ & $12.0 \pm 5.2$ \\
\hline Irri - 6 (Ordinary Rice) & $\mathrm{S} 14$ & $9.0 \pm 3.9$ & $24.7 \pm 7.8$ & $263.0 \pm 34.4$ & $202.0 \pm 34.0$ & $162.0 \pm 52.4$ & $5.6 \pm 1.9$ & $6.7 \pm 0.1$ & $15.7 \pm 7.8$ \\
\hline Tota Basmati & $\mathrm{S} 15$ & $15.4 \pm 3.8$ & $19.8 \pm 6.6$ & $277.0 \pm 44.6$ & $231.0 \pm 32.5$ & $211.0 \pm 52.5$ & $5.5 \pm 1.9$ & $6.6 \pm 0.1$ & $13.2 \pm 6.6$ \\
\hline D. R. & S16 & $13.1 \pm 0.0$ & $13.1 \pm 0.0$ & $111.0 \pm 39.7$ & $170.0 \pm 61.8$ & $177.0 \pm 16.6$ & $7.6 \pm 1.9$ & $4.3 \pm 3.8$ & $10.9 \pm 7.6$ \\
\hline Double Rice & S17 & $8.6 \pm 3.8$ & $27.9 \pm 3.7$ & $52.0 \pm 20.4$ & $71.0 \pm 7.5$ & $167.0 \pm 42.8$ & $5.3 \pm 1.8$ & $40.8 \pm 9.8$ & $17.2 \pm 3.7$ \\
\hline Irri Dagi & $\mathrm{S} 18$ & $<\mathrm{BDL}$ & $34.0 \pm 6.8$ & $136.0 \pm 66.9$ & $<\mathrm{BDL}$ & $184.0 \pm 19.6$ & $5.7 \pm 2.0$ & $34.0 \pm 6.8$ & $15.9 \pm 3.9$ \\
\hline
\end{tabular}


Table 3 Comparison of heavy metals concentrations of rice of the present study with that of previous studies.

\begin{tabular}{|c|c|c|c|c|c|c|c|c|c|}
\hline Origin & $\underset{\left(\mu \mathrm{gkg}^{-1}\right)}{\mathrm{Cd}}$ & $\underset{\left(\mu \mathrm{gkg}^{-1}\right)}{\text { Co }}$ & $\underset{\left(\mu \mathrm{gkg}^{-1}\right)}{\mathrm{Cr}}$ & $\underset{\left(\mu \mathrm{gkg}^{-1}\right)}{\mathrm{Ni}}$ & $\begin{array}{c}\text { Pb } \\
\left(\mu \mathrm{gkg}^{-1}\right)\end{array}$ & $\underset{\left(\mathrm{mgkg}^{-1}\right)}{\mathrm{Cu}}$ & $\underset{\left(\mathrm{mgkg}^{-1}\right)}{\operatorname{Mn}}$ & $\underset{\left(\mathrm{mgkg}^{-1}\right)}{\mathrm{Zn}}$ & Reference \\
\hline Pakistan & $\begin{array}{c}12 \\
(6.3-22.0)\end{array}$ & $\begin{array}{c}12 \\
(2.8-34.0)\end{array}$ & $\begin{array}{c}106 \\
(38.0-277.0)\end{array}$ & $\begin{array}{c}137 \\
(60.0-211)\end{array}$ & $\begin{array}{c}140 \\
(41.0-273)\end{array}$ & $\begin{array}{c}7.7 \\
(3.3-16.5)\end{array}$ & $\begin{array}{c}9.7 \\
(2.9-40.8)\end{array}$ & $\begin{array}{c}14.6 \\
(10.6-33.0)\end{array}$ & This study \\
\hline $\begin{array}{l}\text { Nanhu, } \\
\text { China }\end{array}$ & - & - & $\begin{array}{c}250 \\
(180-350)\end{array}$ & - & $\begin{array}{c}250 \\
(60-490)\end{array}$ & $\begin{array}{c}5.5 \\
(2.87-8.86)\end{array}$ & $\begin{array}{c}36.3 \\
(26.9-48.50)\end{array}$ & $\begin{array}{c}23.2 \\
(21.1-27.1)\end{array}$ & [11] \\
\hline $\begin{array}{l}\text { Tongxiang, } \\
\text { China }\end{array}$ & - & - & $\begin{array}{c}300 \\
(270-340)\end{array}$ & - & $\begin{array}{c}350 \\
(160-560)\end{array}$ & $\begin{array}{c}4.1 \\
(2.40-5.47)\end{array}$ & $\begin{array}{c}36.2 \\
(25.1-46.2)\end{array}$ & $\begin{array}{c}22.6 \\
(18.1-27.5)\end{array}$ & [11] \\
\hline China & $\begin{array}{c}34 \\
(3.6-69.7)\end{array}$ & $\begin{array}{c}169 \\
(55-420)\end{array}$ & $\begin{array}{c}199 \\
(62-424)\end{array}$ & $\begin{array}{c}476 \\
(201-818)\end{array}$ & $\begin{array}{c}355 \\
(167-745)\end{array}$ & $\begin{array}{c}3.3 \\
(2.8-4.5)\end{array}$ & $\begin{array}{c}9.4 \\
(5.8-12.7)\end{array}$ & - & [17] \\
\hline Australia & $\begin{array}{c}8 \\
(8.7-17.1)\end{array}$ & $\begin{array}{c}21 \\
(7-42)\end{array}$ & $\begin{array}{c}144 \\
(15-465)\end{array}$ & $\begin{array}{c}166 \\
(61-356)\end{array}$ & $\begin{array}{c}375 \\
(16-1248)\end{array}$ & $\begin{array}{c}2.9 \\
(1.0-9.4)\end{array}$ & $\begin{array}{c}24.4 \\
(9.2-51.7)\end{array}$ & $\begin{array}{c}17.1 \\
(10.9-24.5)\end{array}$ & [29] \\
\hline India & 380 & - & 183 & 430 & 830 & 2.2 & 1.7 & 16.8 & [29] \\
\hline Bangladesh & $\begin{array}{c}73 \\
(69-77)\end{array}$ & $\begin{array}{c}5 \\
(1.9-7.3)\end{array}$ & $\begin{array}{c}119 \\
(41-217)\end{array}$ & $\begin{array}{c}105 \\
(76-163)\end{array}$ & $\begin{array}{c}19 \\
(5-28)\end{array}$ & $\begin{array}{c}1.6 \\
(1.3-1.9)\end{array}$ & $\begin{array}{c}14.7 \\
(13.2-16.0)\end{array}$ & $\begin{array}{c}13.4 \\
(12.1-14.9)\end{array}$ & [29] \\
\hline
\end{tabular}

\section{Cadmium}

The concentration of $\mathrm{Cd}$ in selected rice samples is tabulated in Table 2. It was observed that highest concentration of $\mathrm{Cd}$ was found in S05 (Tota Kernal-1), numerically $22.0 \mu \mathrm{g} \mathrm{kg}^{-1}$ followed by S06, S15, S16, S04, S14, S13, S17, S07, S02 and finally S12 (Basmati - 110) which has the lowest concentration of $\mathrm{Cd}\left(6.3 \mu \mathrm{gkg}^{-1}\right)$ among all samples. S01, S03, S08, S09, S10, S11, and S18 had Cd content below the detection limits of the technique. The mean concentration of cadmium for all samples was $12.0 \mathrm{\mu gkg}^{-1}$. Comparison of $\mathrm{Cd}$ concentration in Pakistani rice with previous study showed that average concentration of $\mathrm{Cd}$ in Pakistani rice was lower than that of Chinese, Bangladeshi, and Indian Rice; however, Australian rice was less contaminated as compared to Pakistani rice.

\section{Cobalt}

It was observed that the concentration of Co was found lowest in sample S08 (Super Basmati, $2.8 \mu \mathrm{g} \mathrm{kg}^{-1}$ ). The concentration of Co followed the order S09 $<\mathrm{S} 02<\mathrm{S} 01<\mathrm{S} 10<\mathrm{S} 06<$ $\mathrm{S} 05<\mathrm{S} 07<\mathrm{S} 04<\mathrm{S} 13<\mathrm{S} 12<\mathrm{S} 16<\mathrm{S} 15<\mathrm{S} 14$ $<\mathrm{S} 17$ whereas the highest concentration of Co was found in S18 (Irri Dagi, $34 \mu \mathrm{g} \mathrm{kg}^{-1}$ ). Concentration of Co for S03 and S11 were lower than the detection limits of the technique. The mean concentration of Co for all samples was $12.0 \mu \mathrm{g}$ $\mathrm{kg}^{-1}$. Comparison with previous studies showed that the Co ion concentration in Pakistani rice was lower than Australian and Chinese rice whereas Bangladeshi rice had lower concentration of Co than Pakistani rice.

\section{Chromium}

The concentration of $\mathrm{Cr}$ was minimum for S12 (Basmati - 110) and maximum for S15 (Tota Basmati). Minimum and maximum concentration of Cr for S12 and S15 were 38.0 and $277.0 \mu \mathrm{g} \mathrm{kg}^{-1}$, respectively. Mean of concentration for all eighteen samples was found to be $106.20 \mu \mathrm{g} \mathrm{kg}^{-1}$. Concentration of $\mathrm{Cr}$ when compared to previous studies was found to be lower than Bangladeshi, Australian, Indian, Chinese rice. Concentration of $\mathrm{Cr}$ in rice samples when arranged in ascending order yielded the following sequence. S12<S09< $\mathrm{S} 02,<\mathrm{S} 17,<\mathrm{S} 08<\mathrm{S} 06<\mathrm{S} 03<\mathrm{S} 05<\mathrm{S} 11<\mathrm{S} 10$ $<\mathrm{S} 04<\mathrm{S} 16<\mathrm{S} 07<\mathrm{S} 01<\mathrm{S} 18<\mathrm{S} 13<\mathrm{S} 14<$ S15.

\section{Lead}

The $\mathrm{Pb}$ concentration was minimum for S03 (Irri - 9) and maximum for S09 (Super Basmati Shaheen). Minimum and maximum 
concentration of lead for S03 and S09 were 41.0 and $273.0 \mu \mathrm{g} \mathrm{kg} \mathrm{kg}^{-1}$ respectively. Mean of concentration for all eighteen samples was found to be $140.3 \mu \mathrm{g} \mathrm{kg}^{-1}$. Bangladeshi rice had the lowest lead concentration which was followed by Pakistani, Chinese, Australian and Indian rice, arranged in increasing order of concentration. Pakistani varieties when arranged in such order yielded the following sequence $\mathrm{S} 03<\mathrm{S} 08<$ $\mathrm{S} 17<\mathrm{S} 02<\mathrm{S} 12<\mathrm{S} 13<\mathrm{S} 04<\mathrm{S} 06<\mathrm{S} 05<\mathrm{S} 16$ $<\mathrm{S} 01<\mathrm{S} 14<\mathrm{S} 15<\mathrm{S} 09<\mathrm{S} 11<\mathrm{S} 10<\mathrm{S} 07<$ S18.

\section{Nickel}

The average concentration of $\mathrm{Ni}$ in the rice samples was found to be $136.8 \mu \mathrm{g} \mathrm{kg}^{-1}$. Minimum concentration was found in sample S09 (Super Basmati Shaheen). Maximum concentration of nickel was found in sample S15 (Tota Basmati). Concentration of Ni for S09 was $60.0 \mu \mathrm{g} \mathrm{kg}^{-1}$. For sample $\mathrm{S} 15$ concentration of $\mathrm{Ni}$ was found to be $211.0 \mu \mathrm{g} \mathrm{kg}^{-1}$. Comparison of $\mathrm{Ni}$ concentration in Pakistani rice with the rice from other countries revealed that average Ni content is lower from that of Chinese, Indian and Australian rice. However, it is found higher than that of Bangladeshi rice. Following was the sequence of $\mathrm{Ni}$ concentration in Pakistani rice variety. S09 $<$ S03 $<$ S08 $<$ S10 $<$ $\mathrm{S} 06<\mathrm{S} 05<\mathrm{S} 11<\mathrm{S} 01<\mathrm{S} 04<\mathrm{S} 12<\mathrm{S} 13<\mathrm{S} 14$ $<\mathrm{S} 17<\mathrm{S} 16<\mathrm{S} 18<\mathrm{S} 02<\mathrm{S} 07<\mathrm{S} 15$.

\section{Copper}

The average concentration of $\mathrm{Cu}$ in the rice samples was found to be $7.7 \mathrm{mg} \mathrm{kg}$. Minimum concentration of copper was found in sample S08 (Super Basmati). Maximum concentration of $\mathrm{Cu}$ was found in sample $\mathrm{S} 13$ (Irri - 9 (Punjab)). Concentration of $\mathrm{Cu}$ for $\mathrm{S} 08$ was $3.3 \mathrm{mg} \mathrm{kg}^{-1}$. For sample $\mathrm{S} 13$ concentration of $\mathrm{Cu}$ was found to be $16.5 \mathrm{mg} \mathrm{kg}{ }^{-1}$. The concentration of $\mathrm{Cu}$ in Pakistani rice variety arranged in ascending order resulted in the following sequence S08 $<$ S04 $<$ S03 $<$ S17 $<$ S15 $<\mathrm{S} 14<\mathrm{S} 18<\mathrm{S} 02<\mathrm{S} 01<\mathrm{S} 05<\mathrm{S} 16<\mathrm{S} 10<$ S06 $<$ S07 $<$ S09 $<$ S11 $<$ S12 $<$ S13. Comparison with the previous studies revealed that average copper content of Pakistani rice was higher than that of Australian, Indian, Bangladeshi and Chinese rice.

\section{Manganese}

Sample S17 and S18 had the highest concentration of $\mathrm{Mn}$. The concentration of $\mathrm{Mn}$ was lowest in sample S02 (Tota- 1) which was $2.9 \mathrm{mg}$ $\mathrm{kg}^{-1}$. The highest concentration of Mn was found in sample S17 (Double Rice), viz., $40.8 \mathrm{mg} \mathrm{kg}{ }^{-1}$. Average concentration of Mn sample was $9.7 \mathrm{mg}$ $\mathrm{kg}^{-1}$. The concentration of $\mathrm{Mn}$ in Pakistani rice variety arranged in ascending order resulted in the following sequence S02 $<\mathrm{S} 01<\mathrm{S} 16<\mathrm{S} 08<\mathrm{S} 05$ $<\mathrm{S} 06<\mathrm{S} 07<\mathrm{S} 04<\mathrm{S} 15<\mathrm{S} 10<\mathrm{S} 14<\mathrm{S} 03<$ S09 $<$ S13 $<$ S12 $<$ S11 $<$ S18 $<$ S17. Average Mn concentration in Pakistani rice was found lower than that of Australian, Chinese and Bangladeshi rice, whereas, it was found to be higher than that of Indian rice.

\section{Zinc}

The average concentration of $\mathrm{Zn}$ in the rice samples was found to be $14.6 \mathrm{mg} \mathrm{kg}^{-1}$. Minimum concentration of $\mathrm{Zn}$ was found in sample S07 (Super Kernal Basmati). Maximum concentration of Zn was found in sample S03 (Irri - 9). Table 2 records the concentrations of $\mathrm{Zn}$ for the selected samples. Concentration of $\mathrm{Zn}$ for S07 was $10.6 \mathrm{mg}$ $\mathrm{kg}^{-1}$. For sample $\mathrm{S} 03$ concentration of $\mathrm{Zn}$ was found to be $33.0 \mathrm{mg} \mathrm{kg}^{-1}$. From Table 3 it is found that Bangladeshi rice has the lowest $\mathrm{Zn}$ concentration followed by Pakistani rice whereas the rice from other origins was relatively rich in $\mathrm{Zn}$. The concentration of $\mathrm{Zn}$ in Pakistani rice variety arranged in ascending order resulted in the following sequence S07 $<$ S16 $<$ S01 $<$ S10 $<$ S09 $<\mathrm{S} 06<\mathrm{S} 13<\mathrm{S} 05<\mathrm{S} 11<\mathrm{S} 15<\mathrm{S} 08<\mathrm{S} 04<$ $\mathrm{S} 14<\mathrm{S} 18<\mathrm{S} 17<\mathrm{S} 02<\mathrm{S} 12<\mathrm{S} 03$.

The heavy metals were divided into two types based on their concentration level in the rice samples. Tier - 01 was composed of the elements having concentration at parts per billion level. This group comprised of $\mathrm{Cd}, \mathrm{Co}, \mathrm{Cr}, \mathrm{Pb}$, and $\mathrm{Ni}$. Tier 2 elements had their concentration at parts per million level and they were $\mathrm{Cu}, \mathrm{Mn}$, and $\mathrm{Zn}$. A glimpse of tier - 01 and tier - 02 heavy metals distribution can be seen in Fig. 1 and Fig. 2, 
respectively. Least concentration was observed for $\mathrm{Co}$ and $\mathrm{Cd}$ in the selected rice samples whereas highest concentration for $\mathrm{Pb}, \mathrm{Ni}$, and $\mathrm{Cr}$ was observed in S09, S07, and S15, respectively. It is obvious from Table 2 that sample S10 and S11 had very low level of $\mathrm{Cd}, \mathrm{Co}$, and $\mathrm{Pb}$. On the contrary, sample S14 and S15 had relatively high accumulation of tier -01 heavy metals. Fig. 2 summarizes the concentration profile for tier -02 heavy metals. Highest accumulation of $\mathrm{Mn}$ was observed for S17 and S18, whereas, highest concentration of $\mathrm{Zn}$ was found in S03. Highest concentration of $\mathrm{Cu}$ was observed in $\mathrm{S} 13$.

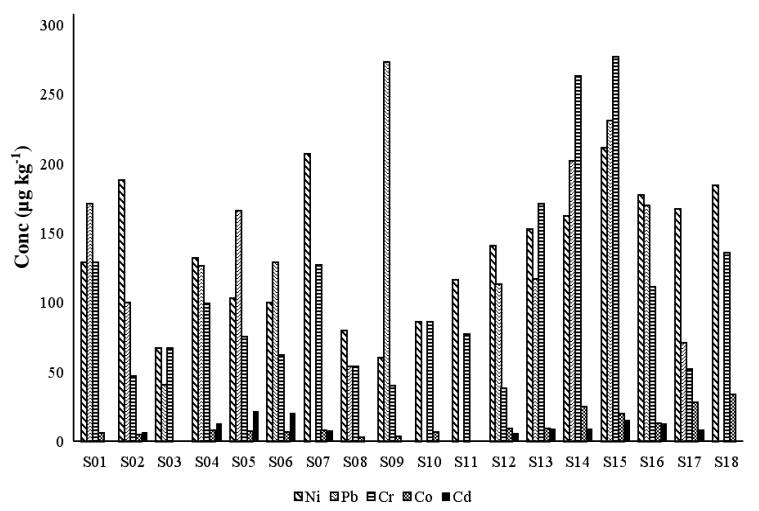

Figure 1. Heavy metal concentration profile for tier - 01 heavy metals $(\mathrm{Cd}, \mathrm{Co}, \mathrm{Cr}, \mathrm{Pb}, \mathrm{Ni})$ in selected rice samples

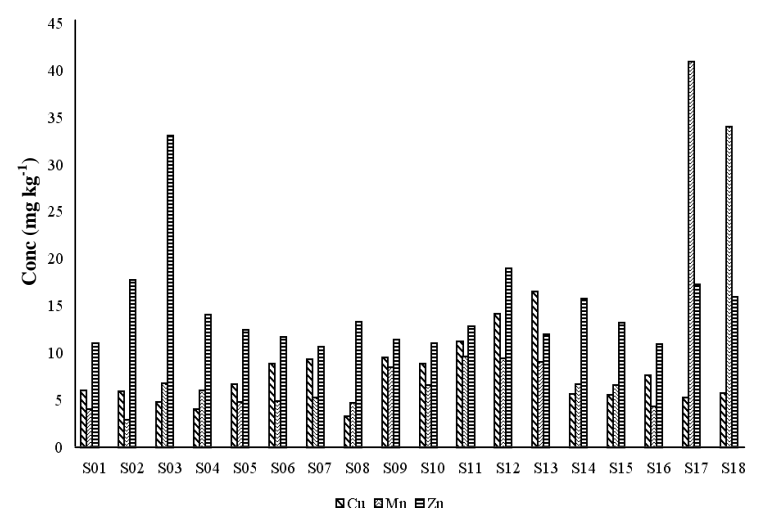

Figure 2. Heavy metal concentration profile for tier - 02 heavy metals $(\mathrm{Cu}, \mathrm{Mn}, \mathrm{Zn})$ in selected rice samples

Pearson correlation coefficient was calculated using the concentrations of heavy metal in rice samples. Table 4 summarizes the values of correlation coefficients. It is observed that there is strong correlation among few heavy metals. Significant positive correlation for a group of elements may be due to same type of interactions between rice and the metal ions [30]. Co and $\mathrm{Cr}$ had a significant positive correlation between them. $\mathrm{Pb}$ had a significant positive correlation with both $\mathrm{Cd}$ and $\mathrm{Cr}$. Moreover, $\mathrm{Ni}$ had a positive significant correlation with each $\mathrm{Cd}, \mathrm{Co}$ and $\mathrm{Cr}$. $\mathrm{Mn}$, on the other hand, was positively correlated with $\mathrm{Co}$ only. It is also observed that $\mathrm{Cu}$ showed no significant correlation with other selected heavy metals. Zn was an element which had a negative correlation with $\mathrm{Cd}, \mathrm{Co}$ and $\mathrm{Pb}$. Remaining values of the correlation coefficients were statistically insignificant.

Table 4. Correlation coefficients between heavy metal concentrations in rice grains.

\begin{tabular}{lccccccc}
\hline & $\mathbf{C o}$ & $\mathbf{C r}$ & $\mathbf{P b}$ & $\mathbf{N i}$ & $\mathbf{C u}$ & $\mathbf{M n}$ & $\mathbf{Z n}$ \\
\hline $\mathbf{C d}$ & -0.192 & 0.005 & $0.396^{*}$ & $-0.569^{*}$ & -0.273 & -0.263 & $-0.545^{*}$ \\
$\mathrm{Co}$ & & $0.467^{*}$ & 0.077 & $0.548^{*}$ & -0.241 & $0.776^{*}$ & $0.436^{*}$ \\
$\mathbf{C r}$ & & & $0.467^{*}$ & $0.542^{*}$ & -0.070 & -0.075 & -0.177 \\
$\mathbf{P b}$ & & & & 0.146 & 0.121 & -0.258 & $-0.562^{*}$ \\
$\mathrm{Ni}$ & & & & & 0.004 & 0.245 & -0.180 \\
$\mathbf{C u}$ & & & & & & -0.106 & -0.229 \\
$\mathrm{Mn}$ & & & & & & & 0.159 \\
\hline Correlation is statistically significant at the $\mathbf{0 . 0 5}$ probability level
\end{tabular}

\section{Conclusion}

In this study, determination of heavy metals was carried out in different varieties of rice found in Pakistan, using Atomic Absorption Spectroscopy. Values obtained from this study were compared with the results from other countries. It was observed that the level of toxic heavy metals in Pakistani rice is quite low as compared to rice from other developing countries; especially Bangladesh. Some metals were present below the detection limits. Fortunately, the selected rice samples were relatively safe from heavy metal toxicity as its high level can cause severe health risk for human beings.

\section{References}

1. J. Zhang, H. Li, Y. Zhou, L. Dou, L. Cai, L. Mo and J. You, Environ. Pollut., 235 (2018) 710. https://doi.org/10.1016/j.envpol.2017.12.1 $\underline{06}$ 
2. Abedullah, S. Kouser and K. Mushtaq, Pak. Econ. Soc. Rev., (2007) 231.

3. G. Carbonell, R. M. de Imperial, M. Torrijos, M. Delgado and J. A. Rodriguez, Chemosphere, 85 (2011) 1614. https://doi.org/10.1016/j.chemosphere.201 1.08 .025

4. J. Hargreaves, M. Adl and P. Warman, Agr. Ecosyst. Environ., 123 (2008) 1. https://doi.org/10.1016/j.agee.2007.07.004

5. U. Ashraf, S. Hussain, S. A. Anjum, F. Abbas, M. Tanveer, M. A. Noor and X. Tang, Plant Physiol. Biochem., 115 (2017) 461.

https://doi.org/10.1016/j.plaphy.2017.04.0 $\underline{19}$

6. M. A. Zoroddu, J. Aaseth, G. Crisponi, S. Medici, M. Peana and V. M. Nurchi, $J$. Inorg. Biochem., 195 (2019) 120.

https://doi.org/10.1016/j.jinorgbio.2019.03 .013

7. L. Jorhem, C. Åstrand, B. Sundström, M. Baxter, P. Stokes, J. Lewis and K. P. Grawé, Food Addit. Contam., 25 (2008) 841.

https://doi.org/10.1080/026520307017010 $\underline{58}$

8. A. Salam, S. M. Shaheen, S. Bashir, I. Khan, J. Wang, J. Rinklebe, F. U. Rehman and $\mathrm{H}$. Hu, J. Environ. Manage., 237 (2019) 5 .

https://doi.org/10.1016/j.jenvman.2019.02. $\underline{047}$

9. C. Aydinalp and S. Marinova, Pol. J. Environ. Stud., 12 (2003).

10. G. Zalidis, S. Stamatiadis, V. Takavakoglou, K. Eskridge and N. Misopolinos, Agr. Ecosyst. Environ., 88 (2002) 137.

https://doi.org/10.1016/S0167-

8809(01)00249-3

11. F. Zeng, S. Ali, H. Zhang, Y. Ouyang, B. Qiu, F. $\mathrm{Wu}$ and G. Zhang, Environ. Pollut., 159 (2011) 84. https://doi.org/10.1016/j.envpol.2010.09.0 $\underline{19}$

12. K. Bora, D. Sarkar, K. Konwar, B. Payeng, K. Sood, R. K. Paul, R. Datta, S. Das, P. Khare and T. Karak, Food Res. Int., 120 (2019) 851. https://doi.org/10.1016/j.foodres.2018.11.0 $\underline{49}$

13. A. Papafilippaki, D. Gasparatos, C. Haidouti and G. Stavroulakis, Global Nest J., 9 (2007) 201. https://doi.org/10.30955/gnj.000461

14. M. Shahid, C. Dumat, S. Khalid, E. Schreck, T. Xiong and N. K. Niazi, J. Hazard. Mater., 325 (2017) 36. https://doi.org/10.1016/j.jhazmat.2016.11. $\underline{063}$

15. J. Fu, Q. Zhou, J. Liu, W. Liu, T. Wang, Q. Zhang and G. Jiang, Chemosphere, 71 (2008) 1269.

https://doi.org/10.1016/j.chemosphere.200 7.11.065

16. R. Singh and M. Agrawal, Ecotox. Environ. Safe., 73 (2010) 632.

https://doi.org/10.1016/j.ecoenv.2010.01.0 $\underline{20}$

17. Q. Zhao, Y. Wang, Y. Cao, A. Chen, M. Ren, Y. Ge, Z. Yu, S. Wan, A. Hu and Q. Bo, Sci. Total Environ., 470 (2014) 340.

https://doi.org/10.1016/j.scitotenv.2013.09. $\underline{086}$

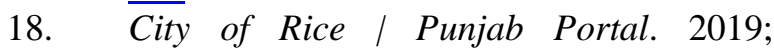
Available from:

https://www.punjab.gov.pk/hafizabad_city of_rice.

19. K. Sharafi, M. Yunesian, R. N. Nodehi, A. H. Mahvi and M. Pirsaheb, Ecotox. Environ. Safe., 176 (2019) 64. https://doi.org/10.1016/j.ecoenv.2019.03.0 $\underline{72}$

20. K. Sharafi, M. Yunesian, A. H. Mahvi, M. Pirsaheb, S. Nazmara and R. N. Nodehi, Ecotox. Environ. Safe., 175 (2019) 128. https://doi.org/10.1016/j.ecoenv.2019.03.0 $\underline{56}$

21. P. Pandey and R. S. Dubey, In: Advances in Rice Research for Abiotic Stress Tolerance (M. Hasanuzzaman, M. Fujita, K. Nahar and J. K. Biswas Eds) Woodhead Publishing, NY (2019) 313.

22. O. Ojuederie and O. Babalola, Int. J. Environ. Res. Public Health, 14 (2017) 1504.

https://doi.org/10.3390/ijerph14121504

23. J. Martínez-Cortijo and A. Ruiz-Canales, Agr. Water Manage., 210 (2018) 108. 
https://doi.org/10.1016/j.agwat.2018.07.03 7

24. N. Vongdala, H. D. Tran, T. Xuan, R. Teschke and T. Khanh, Int. J. Environ. Res. Public Health, 16 (2019) 22. https://doi.org/10.3390/ijerph16010022

25. K. Rehman, F. Fatima, I. Waheed and M. S. H. Akash, J. Cell. Biochem., 119 (2018) 157.

https://doi.org/10.1002/jcb.26234

26. J. Kalita, A. K. Pradhan, Z. M. Shandilya and B. Tanti, Rice Sci., 25 (2018) 235.

https://doi.org/10.1016/j.rsci.2018.06.007

27. R. Xiao, D. Guo, A. Ali, S. Mi, T. Liu, C. Ren, R. Li and Z. Zhang, Environ. Pollut., 248 (2019) 349. https://doi.org/10.1016/j.envpol.2019.02.0 $\underline{45}$

28. M. Csuros, Environmental sampling and analysis for technicians (Lewis Publishers, CRC press, Washington, D.C.) (2018) 12.

29. M. A. Rahman, M. M. Rahman, S. M. Reichman, R. P. Lim and R. Naidu, Ecotox. Environ. Safe., 100 (2014) 53. https://doi.org/10.1016/j.ecoenv.2013.11.0 24

30. S. Jiang, J. Wu, Y. Feng, X. Yang and C. Shi, J. Agric. Food. Chem., 55 (2007) 9608.

https://doi.org/10.1021/jf071785w 